\title{
Vascular Lesions of
}

\section{the Internal Auditory Canal}

\begin{abstract}
We report here two cases of vascular tumors arising within the internal auditory canal, both of which presented with cerebellopontine angle symptoms and simulated acoustic neurinomas. The first case was an arteriovenous malformation that caused moderate sensorineural hearing loss, tinnitus, vertigo with lateropulsion, facial weakness, and trigeminal hypoesthesia on the same side. The second case was a venous angioma, to our knowledge the first ever reported in this location, which presented with sudden complete deafness and progressive hemifacial spasm. The latter subsided completely after successful total extirpation of this unique tumor. The literature on these extremely rare lesions is also reviewed.
\end{abstract}

Isolated vascular lesions arising within the internal auditory canal are extremely rare. ${ }^{1-6}$ There were only two vascular lesions among the 627 tumors of the cerebellopontine angle (CPA) and internal auditory canal (IAC) operated on at the Department of Neurosurgery of the Nordstadt City Hospital in Hannover between October 1977 and August 1988. The other tumors included 500 acoustic neurinomas $(79.7 \%)$, eight facial neurinomas (excluding other neurinomas within the temporal bone), four neurinomas of the caudal cranial nerves at the jugular foramen and the CPA, 86 meningiomas (13.7\%), which thus constituted the second most common tumor of this region, and 27 epidermoids (4.3\%) (Table 1).

Histopathologically, intracranial vascular malformations are divided into five main categories: cavernous angioma, telangiectasis, saccular (congenital) and fusiform (atherosclerotic) aneurysms, arteriovenous fistulae or aneurysms (arteriovenous malformation [AVM]), and venous angiomas. This last category of congenital, benign vascular malformations is a subgroup consisting of lesions found on angiographic and histopathologic examination to be composed of venous structures only. ${ }^{7-10}$

Duvoisin and Melvin ${ }^{11}$ found that 15 to $20 \%$ of all intracranial vascular dysplasias were located within the posterior cranial fossa and tentorium. Aneurysmatic dysplasias within the CPA are much more frequent than angiomatous malformations. Kendal and Symon, ${ }^{12}$ for example, found only two vascular malformations as against
13 aneurysms or ectatic arteries among 208 patients presenting with CPA symptoms. Verbiest ${ }^{13}$ summarized 108 cases of AVMs within the posterior cranial fossa, among which only a single case of a vascular dysplasia was found located subarachnoidally within the CPA and cauda to the seventh and eighth cranial nerves. Further reports of sporadic vascular lesions within the CPA were made by Eisenbrey and Hegarty, ${ }^{14}$ Dereux and Debert, 15 Green et al, ${ }^{8}$ Drake, ${ }^{16}$ Yasargil, ${ }^{17}$ and Katayama and coworkers. ${ }^{4}$

The first reported case of an isolated vascular lesion within the IAC was published in 1967 by Castaigne et al. 18 Saudaresan and coworkers ${ }^{6}$ reported a further three cases, one AVM and two cavernous hemangiomas, which caused hearing loss and facial palsy or spasm.

Our first case ${ }^{5}$ was an AVM within the IAC, which presented with vestibulocochlear, facial, and trigeminal involvement. The second case was a venous angioma that caused sudden loss of hearing, followed 3 years later by hemifacial spasm on the same side.

\section{CASE REPORTS}

\section{Case 1}

A 50-year-old woman had paroxysms of vertigo and unsteady gait, together with neck stiffness causing occipi- 
Table 1. Incidence of Various Tumors Arising at the CPA and IAC

\begin{tabular}{lrc}
\hline Tumor & No. & $\%$ \\
\hline Acoustic neurinomas & 500 & 79.7 \\
Facial neurinomas & 8 & \\
Neurinomas of IX, X, and XI & 4 & \\
Meningiomas & 86 & 13.7 \\
Epidermoids & 27 & 4.3 \\
Vascular tumors & 2 & 0.3 \\
Aneurysms & 0 & \\
Total & 627 & $100 \%$ \\
\hline
\end{tabular}

tal headache radiating to the retroauricular region. She also noticed very mild facial asymmetry and disturbance of taste on the same side of her tongue.

These complaints subsided gradually within 10 weeks but recurred in accentuated form 6 months later. They were then accompanied by tinnitus and mild perceptive hearing loss of about 20 to $30 \mathrm{~dB}$, deteriorating further to 40 to $60 \mathrm{~dB}$ a few weeks later. The patient further reported hypoesthesia on the same side of her face accompanied by sporadic retrobulbar stabbing pains.

On clinical examination we found mild right-sided hypoesthesia of V2 and V3, a diminished corneal reflex, a slight peripheral facial nerve palsy affecting the lower part of the face, and a diminished sense of taste on the same side of the tongue.

Brainstem-evoked response audiometry showed slight delay of the J1-J5 latencies with normal wave ampli- tudes. The electronystagmogram showed left-sided spontaneous nystagmus and the caloric test revealed hypofunction of the right labyrinth. Computed tomography (CT) showed mild dilation of the IAC caused by a small intrameatal, cystic tumor, which was verified by air CT.

The tumor was first explored via a subtemporal, middle cranial fossa approach. After deroofing the IAC, a red pulsatile vascular mass causing antero- and inferomedial compression and displacement of the seventh and eighth cranial nerves was seen. The tumor was supplied by a vascular loop arising from a branch of the anterior inferior cerebellar artery (AICA) and entering the IAC. Venous drainage was into the lateral bulbopontine vein.

On account of these vascular connections, the tumor was not excised by this route and the patient was referred to our hospital where we performed a retrosigmoidal (lateral suboccipital) craniectomy. The IAC was drilled open as far as the fundus, where we found adhesion between the AVM and the dura of the IAC (Fig. 1A, B).

After coagulation of the feeding arterial loop and the draining venule, the vascular tumor stopped pulsating and decreased in size. Meticulous extirpation was thus possible without injury to the seventh and eighth cranial nerves.

Postoperatively, the hearing loss had deteriorated to deafness, the tolerable tinnitus persisted unchanged, and the vertigo initially worsened but showed complete remission within a few weeks.

The facial palsy also first increased to subtotal palsy but recovered within 3 weeks apart from slight synkinesia at the angle of the mouth.

A

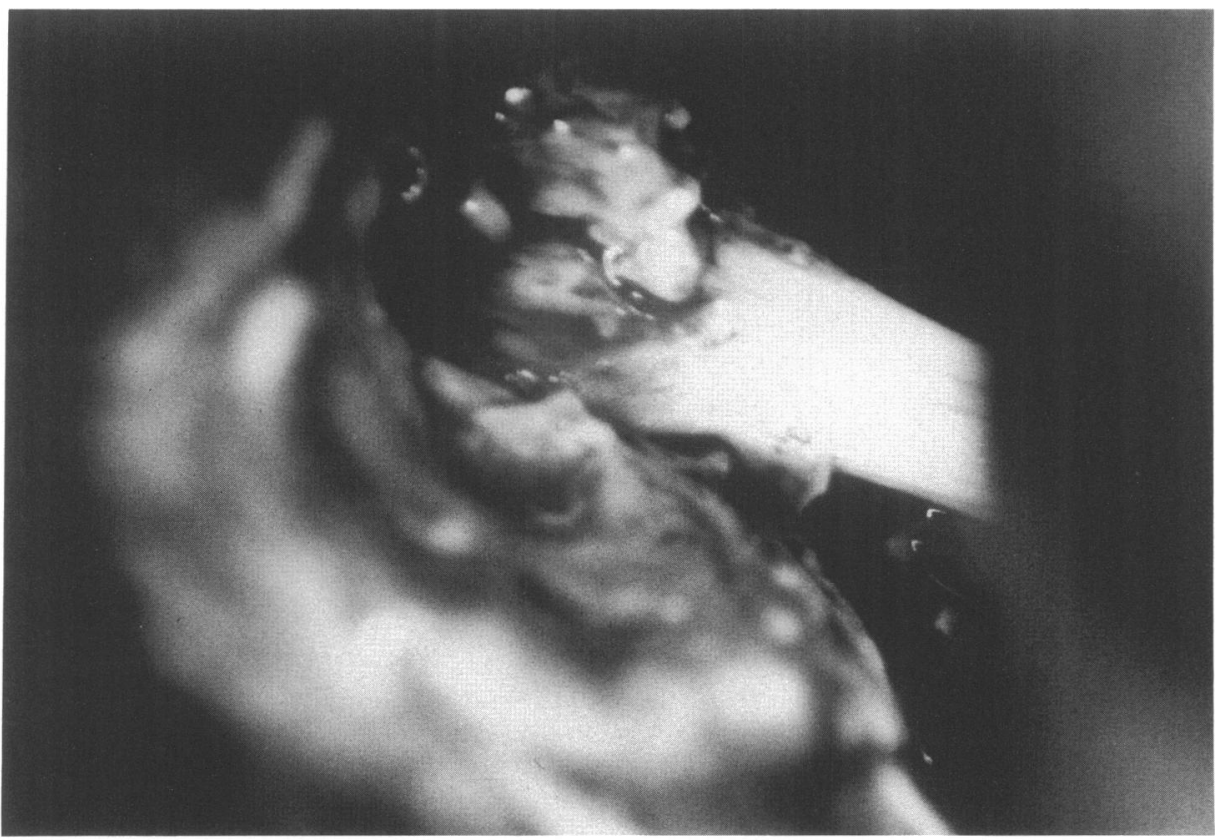

Figure 1. A, B: Intraoperative photograph showing the AVM (case 1) adhering to the seventh and eighth cranial nerves within the internal auditory canal. Note the draining venule (retractor) compressing the fifth nerve and the small feeding arteriole (branch of the anterior inferior cerebellar artery) compressing the seventh and eighth nerves from below. (Figure continued on next page) 


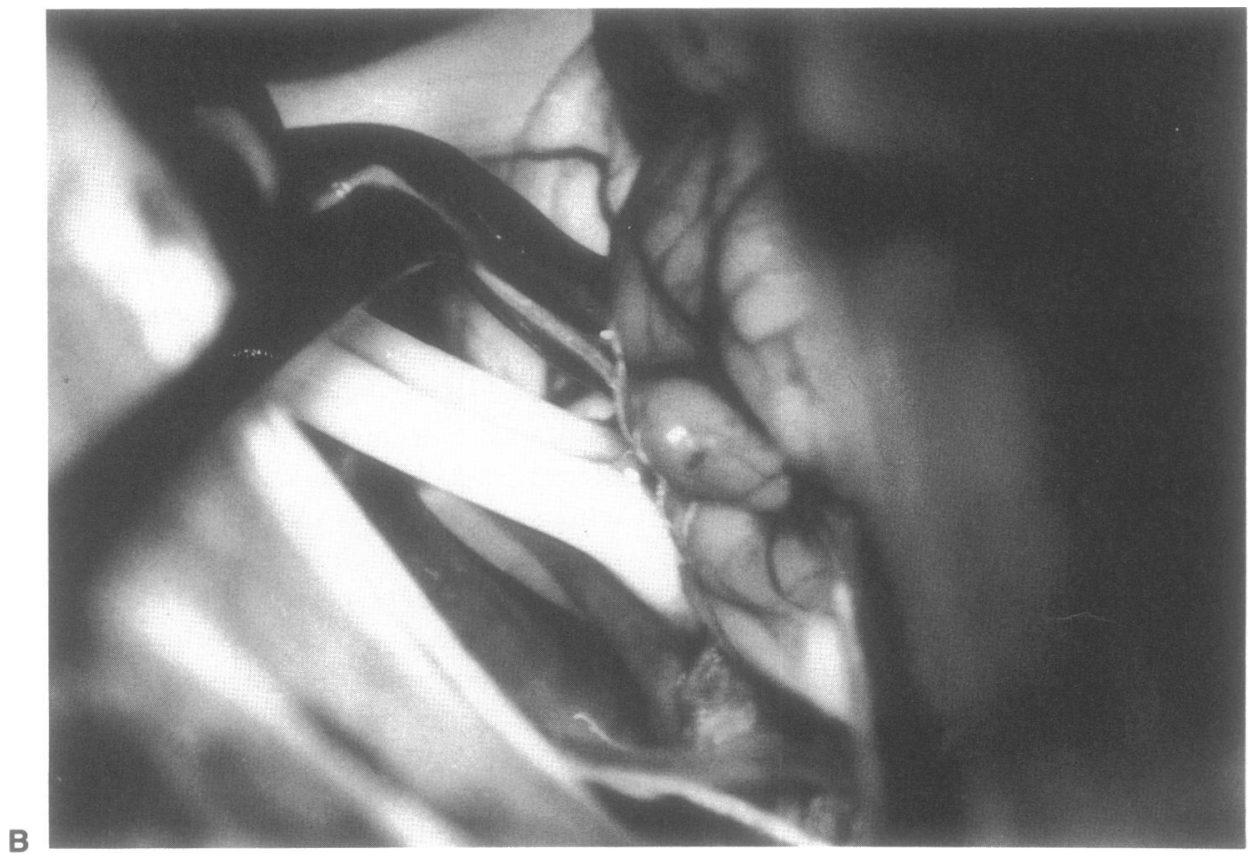

Figure 1, cont.

\section{Case 2}

A 58-year-old woman experienced sudden complete loss of hearing on the right side with tolerable tinnitus. Despite rheologic infusions, the deafness persisted. She also complained of vertigo after rapid change of posture. A cranial CT scan was performed but failed to show any pathologic changes in the IAC.

The patient remained stable until, 2 years later, progressive hemifacial spasm developed on the same side.
This new symptom prompted her ear, nose, and throat specialișt to perform a magnetic resonance imaging (MRI) examination, which revealed an inhomogeneous, intrameatal tumor with increased signal intensity on $\mathrm{T} 1$ scans (Fig. 2A).

A preoperative CT scan (Fig. 2B) also confirmed an inhomogeneous, slightly enhancing, cystic tumor located in the IAC and causing no dilation or bony erosion.

A cystic neurinoma of the eighth cranial nerve was suspected and the tumor was operated on at our hospital on
A

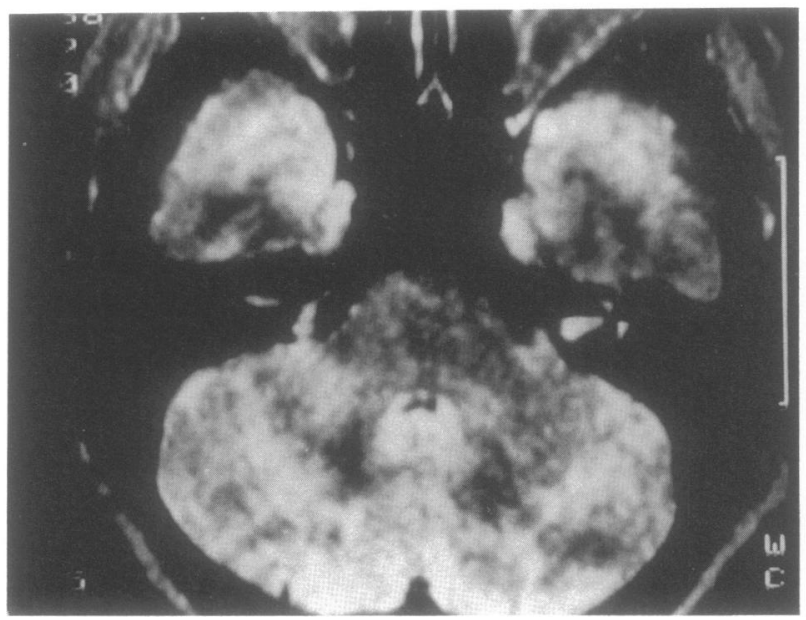

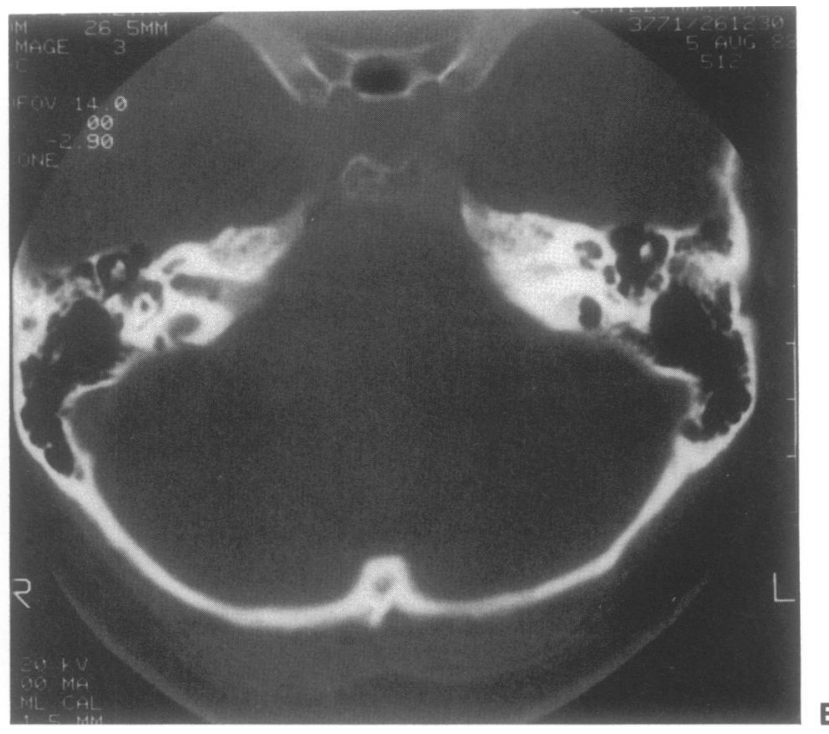

B

Figure 2. A: Magnetic resonance imaging of the venous angioma showing high signal intensity within the internal auditory canal. B: High resolution CT with bony fenestration. Note the low-density, ill-circumscribed, cystic appearance of the angioma. 
August 8, 1988. After performing a posterior fossa retrosigmoidal craniectomy and drilling open the posterior wall of the IAC as far as the fundus, we saw a vascularized, bluish-red pulsating tumor. It was carefully dissected from the neural structures (seventh and eighth cranial nerves) and extirpated (Fig. 3A-C).

The postoperative course was uneventful, the deafness remained but the tinnitus improved slightly. The hemifacial spasm vanished immediately and slight weakness of the facial nerve at the angle of the mouth had disappeared within 3 months of surgery.

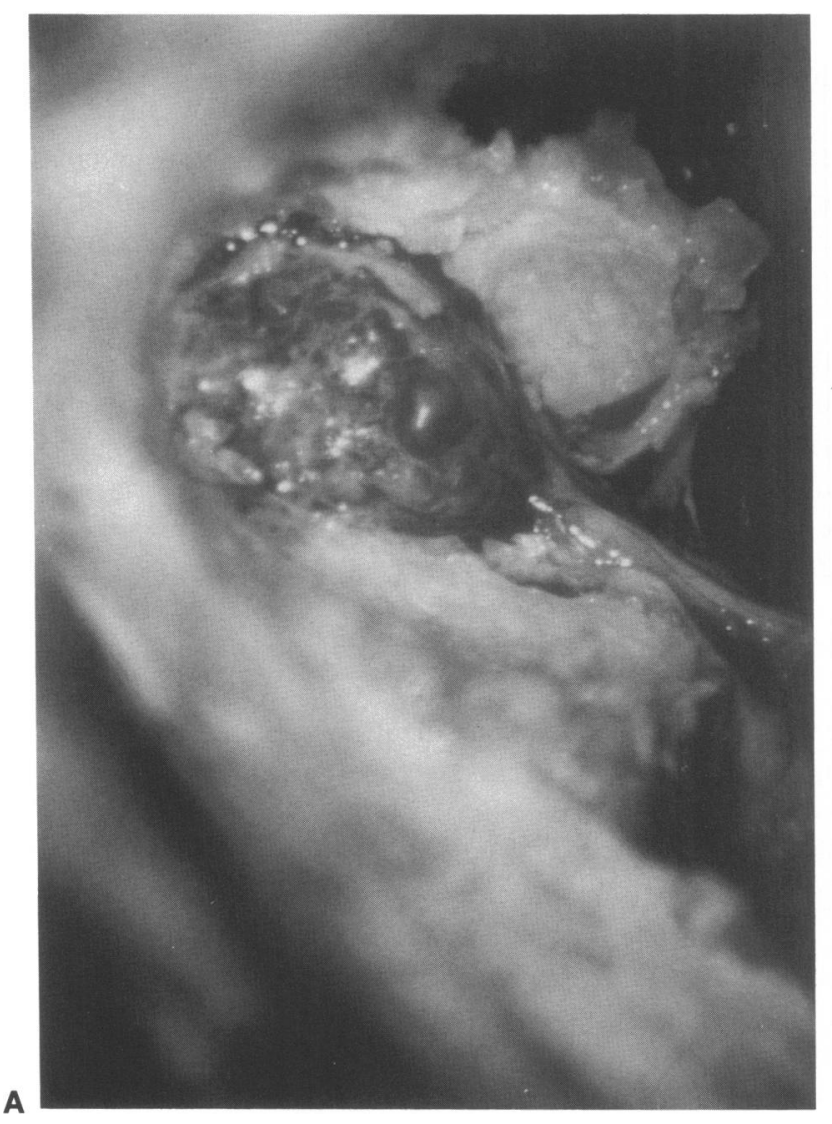

Figure 3. A: The venous angioma, appearing as a bluish pulsatile tumor within the internal auditory canal, which has been drilled open as far as the fundus. Note the close contact to the seventh and eighth nerves. B: The venous angioma totally excised from the internal auditory canal; the seventh and eighth cranial nerves remain intact. C: Postoperative computed tomograph with bony fenestration; note the retrosigmoidal craniectomy, the opened internal auditory canal, and the intact posterior semicircular canal.

\section{DISCUSSION}

Vascular compression of the fifth, seventh, and eighth cranial nerves at the CPA caused by vascular loops has been known since Dandy. 5,11-13,16 Similar observations have been reported by Sunderland, 19 particularly compression caused by thick-walled, atherosclerotic blood vessels.

The vascular compression causes neuralgia if a sensory nerve is affected and spasm if a motor nerve is

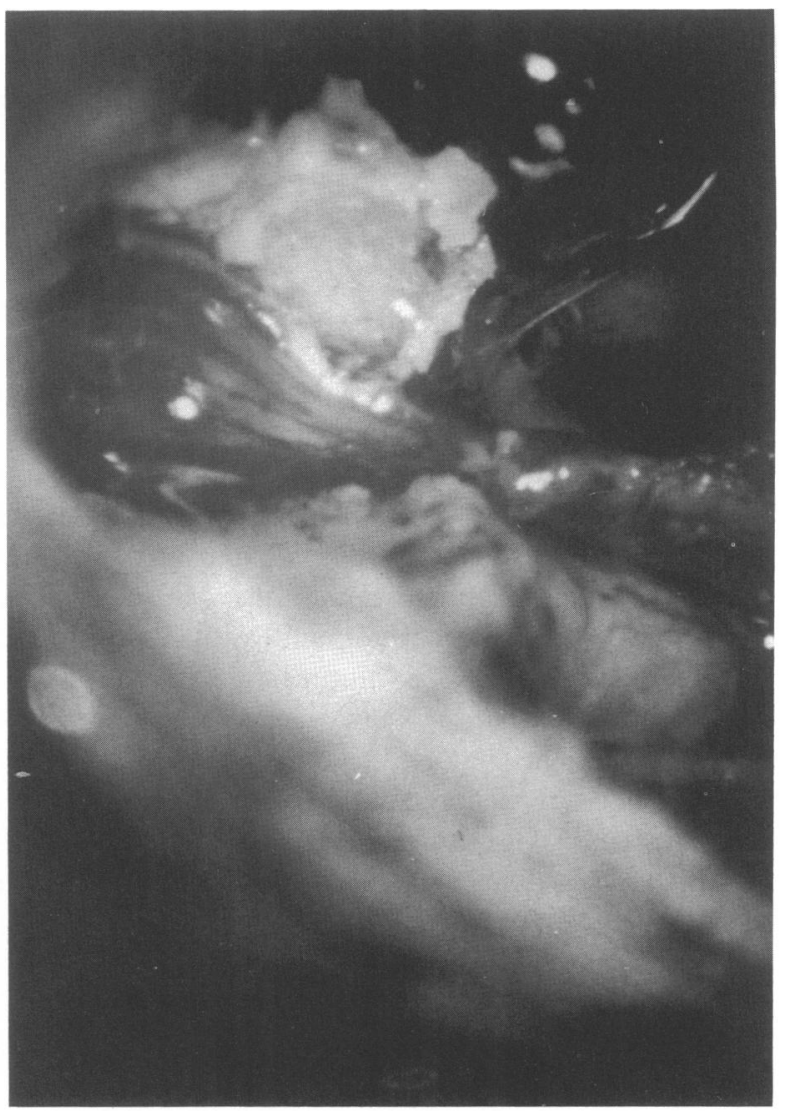

B

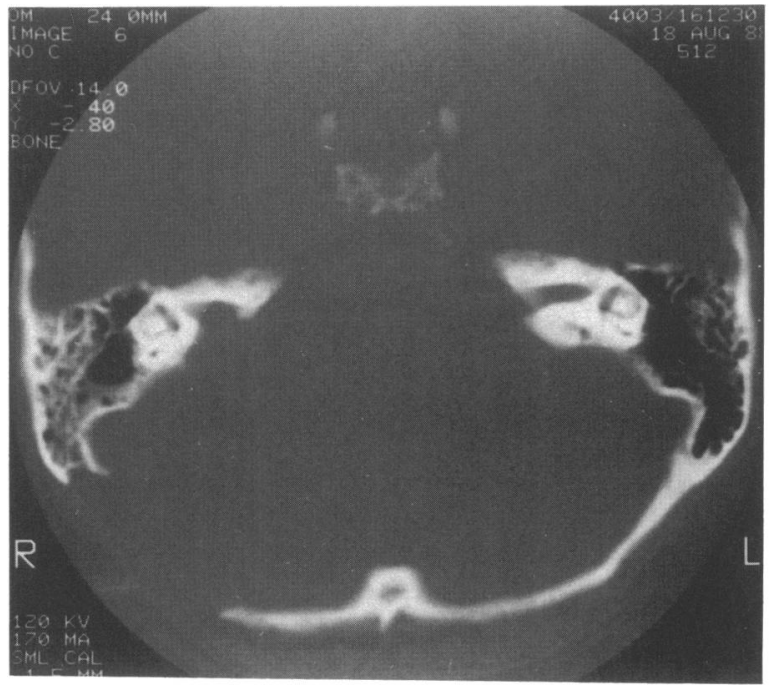




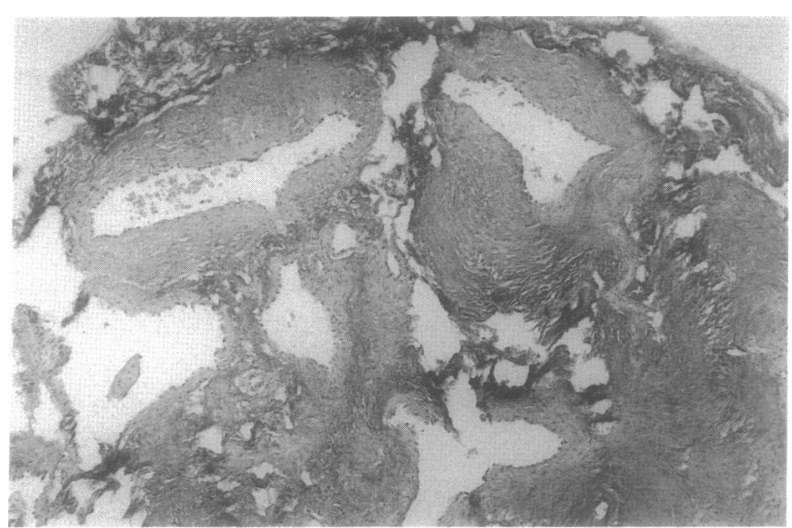

Figure 4. The histologic appearance of the venous angioma; note the absence of arterial structures, the thickened, sclerosed walls of the venules with scanty elastic membrane, and the sclerotic stroma (E. van Gieson stain; $\times 20$.)

affected. Vestibulocochlear symptoms such as hearing loss, tinnitus, dizziness, and vertigo are produced when the eighth cranial nerve is involved.

It is important to stress that only the central, unmyelinated portions of these cranial nerves are vulnerable to the pulsatile compression caused by vascular lesions. In the case of the eighth cranial nerve, the central segment extends as far as the internal auditory meatus and can therefore be affected by an intrameatal vascular lesion.

Following the pioneer work of Janetta and coworkers ${ }^{20}$ and later experience reported by other authors, ${ }^{21,22}$ microvascular decompression has become established as a highly successful technique for healing such disorders.

In the first of our two patients, the vascular lesion (an AVM) affected the seventh, eighth, and fifth cranial nerves, whereas in the second case (venous angioma) only the seventh and eighth nerves were affected.

Both patients first showed sensorineural hearing loss, in the case of the AVM mild hearing loss of 15 months' duration and in the case of the venous angioma sudden complete deafness. Facial nerve affection followed later in the form of a mild palsy in the first case and development of hemifacial spasm 2 years after the initial symptoms in the second.

The compression of the fifth cranial nerve in the first case was caused by the draining venous loop of the AVM, and the retroauricular stabbing can be interpreted as resulting from compression of the intermedius nerve, socalled intermedius neuralgia. ${ }^{23}$

In the three cases reported by Sundearesan and coworkers, ${ }^{6}$ one AVM and two cavernous hemangiomas, there was also early hearing loss, followed later by facial palsy in two cases and facial spasm in the third. The duration of these symptoms also varied between 15 months and more than 10 years.

The case published by Katayama et $\mathrm{al}^{4}$ was a cryptic angioma, related to the acoustic nerve itself at the internal auditory meatus, which bled a few times and presented with a cerebellopontine cistern hemorrhage. The patient had progressive hearing loss terminating in deafness within 1 month, accompanied by facial palsy and taste disturbance as well as recurrent headache and nausea due to bleeding into the cerebellopontine cistern.

The first case, which had previously been explored via a middle cranial fossa approach, ${ }^{24}$ was reoperated on by us via a posterior fossa (retrosigmoid) craniectomy with opening of the IAC as far as the fundus. This route is undoubtedly safer for removing vascular lesions than other available approaches to the IAC, especially if the feeding arterial loop or the draining venules of AVMs are to be ligated or coagulated within the CPA.

Both of our cases showed complete deafness after extirpation of the vascular lesion. The coagulation and the avulsion trauma caused by intraoperative traction on the eighth nerve cause irreversible nutritive and structural damage to the auditory nerve. ${ }^{25,26}$

On the other hand, as in acoustic neurinoma surgery, the facial nerve was successfully preserved. The preoperative hemifacial spasm disappeared immediately, while the facial weakness first increased to subtotal facial palsy, mainly affecting the lower part of the face, but showed complete remission within 3 to 6 months postoperatively. The taste disturbance also resolved completely.

Although rare, vascular lesions should also be considered in the differential diagnosis of intrameatal tumors, especially when hearing loss is associated with facial and/ or trigeminal involvement. An intrameatal acoustic neurinoma rarely causes facial palsy or spasm, which is more common with neurinomas of the facial nerve. These seldom arise within the IAC but more often from the vertical, geniculate, or tympanic portions of the fallopian canal.2,27

Neuroradiologic diagnostic procedures (CT, MRI, or angiography) are mandatory in differentiating these vascular lesions from others. On CT scans, the vascular lesions appear as poorly circumscribed masses of slightly increased density within the CPA with equivocal erosion of the internal auditory meatus. There is heterogeneous enhancement of an onion-like structure attached to the IAC and causing slight medial displacement of the pons. Angiography usually fails to reveal any tumor staining or abnormal vascularity, but MRI provides excellent information on the extension and consistency of the vascular tumor and its relation to the other neural structures within the IAC (Fig. 1).

Meningiomas of the CPA can occasionally invade the IAC, producing similar clinical syndromes, but, on account of their vascularity, their broad-based extension along the posterior surface of the petrous bone, and their occasional hypercalcification, they are easily distinguished on neuroradiologic investigation.

Aneurysms may arise from the AICA at the level of the internal auditory meatus and present with dizziness, unsteady gait, or hearing loss. ${ }^{19,28}$ They also occasionally 
show spontaneous thrombosis that requires no further treatment. ${ }^{29}$

A more frequent vascular lesion of the CPA, however, is the megadolichobasilar anomaly, which consists of an elongated, tortuous course of vertebral and basilar arteries. ${ }^{30}$ The dilated blood vessels form a loop, which can be verified at the CPA by MRI and can lead to pressure necrosis of the posterior surface of the petrous temporal bone or even to dilation of the IAC.

Vascular lesions at the IAC, especially AVMs or angiomas measuring more than $3 \mathrm{~mm}$ in diameter, are a definite indication for surgery on account of the danger of acute subarachnoid hemorrhage. 31

Microsurgical techniques, aided by intraoperative monitoring of brainstem-evoked auditory potentials and preceded by thorough preoperative neuroradiologic diagnostic procedures, have facilitated the management of these vascular tumors and permit an excellent outcome.

\section{REFERENCES}

1. Babin RW, Fratkin JD, Cancilla PA: Hamartomas of the cerebellopontine angle and internal auditory canal. Arch Otolaryngol 106:500-502, 1980

2. Fisch U, Ruettner J: Pathology of intratemporal tumors involving the facial nerve. In Fisch U (ed): Facial nerve surgery. Birmingham, AL: Aesculapius; 1977, pp. 448-456

3. Glasscock ME, Smith PG, Schwaber MK, Nissen AJ: Clinical aspects of osseous hemangiomas of the skull base. Laryngoscope 94:869-874, 1984

4. Katayama Y, Tsubokawa T, Yoshida K: Angioma of the cerebellopontine cistern simulating acoustic neurinomas. Surg Neurol 28:284-286, 1987

5. Penkert G, Samii M, Haid T, Rettinger G: Angiomatöse Fehlbildung des inneren Gehörgangs mit den Leitsymptomen Schwindel und Ohrensausen. HNO 33:17-22, 1985

6. Sundaresan N, Eller T, Ciric T: Hemangiomas of the internal auditory canal. Surg Neurol 6:119-121, 1976

7. Cushing H, Baily P: Tumors arising from the blood vessels of the brain. Springfield IL: Charles C. Thomas, 1928

8. Green JR, Vaughan RJ: Blood vessel tumors and hematomas of the posterior fossa in adolescence. Angiology 23:474-487, 1972

9. Malik GM, Morgan JK, Boulous RS, Ausman JI: Venous angiomas: An underestimated cause of intracranial hemorrhage. Surg Neurol 30:350-358, 1988

10. Zuelch KJ: Biologie und Pathologie der Hirngeschwülste. Berlin: Springer-Verlag, 1988; pp 556-565

11. Duovoisin RC, Melvin DY: Posterior fossa aneurysms. Neurology (Minneap) 15:231-241, 1965

12. Kendall $\mathbf{B}$, Symon L: Investigation of patients presenting with cerebellopontine angle syndromes. Neuroradiology 13:65-84, 1977
13. Verbiest $\mathrm{H}$ : Arterial and arteriovenous aneurysms of the posterior fossa. Psychiatr Neurol Neurochir 65:329-369, 1962

14. Eisenbrey AB, Hegarty WM: Trigeminal neuralgia and arteriovenous aneurysm of the cerebellopontine angle. J Neurosurg 13: 647-649, 1956

15. Dereux J, Debert R: Syndromes de l'angle pontocerebelleux par lésion et malformations vasculaires. Sem Hop Paris 36:18491851,1960

16. Drake CG: Cerebello-pontine angel arterio-venous malformations. Adv Neurosurg 1:265, 1973

17. Yasargil MG: Mikrochirurgie der Kleinhirnbrückenwinkel Tumoren. In Plester D, Wende, Nakayama (eds): Berlin: SpringerVerlag, 1978; pp 215-257

18. Castaigne P, Pertuiset B, Cambier J, Brunet P: Aneurisme de l'artere auditive interne revele par une paralysie faciale recidiviante. Presse Med 75:2493-2496, 1967

19. Sunderland $S$ : The arterial relations of the internal auditory meatus. Brain 68:23-27, 1945

20. Janetta PJ, Abbasy M, Marcon JC, Ramos FM, Albin MS: Etiology and definitive microsurgical treatment of hemifacial spasm. J Neurosurg 47:321-328, 1977

21. Samii M, Ohlemutz A: Early experience in vascular decompression for vestibulo-cochlear malfunction. In Samii M, Janetta PJ (eds): The Cranial Nerves. Berlin: Springer, 1981; pp 556-558

22. Samii M: Pathogenese und operative Behandlung des Spasmus facialis. Aktuel Neurol 10:11-17, 1983

23. Penkert G: Zur Intermediusneuralgie. HNO 34:389-393, 1986

24. Wigand ME, Rettinger G, Haid T, Berg M: Die Ausräumung von Oktavus-neurinomen des KHBW mit transtemporalem Zugang über die mittlere Schädelgrube. HNO 33:11-16, 1985

25. Lumenta C, Reschofsky K, Bock W: Effects of cerebellar retractions on brainstem auditory evoked potentials in an animal model of cerebellopontine angle tumor. Surg Neurol 29:108114,1988

26. Sekiya T, Okabe S, Iwabuchi T: Damage of the peripheral auditory system after operations in the cerebellopontine angle. Surg Neurol 30:117-124, 1988

27. Lo WWM, Brackman DE, Shelton C: Facial nerve hemangioma. Ann Otol Rhinol Laryngol 98:160-161, 1989

28. Porter RJ, Eyster EF: Aneurysm in the anterior inferior cerebellar artery at the internal auditory meatus: Report of a case. Surg Neurol 1:27-28, 1973

29. Valavanis A: Computertomographie und Kernspintomographie und digitale Subtraktionsangiographie des Felsenbeins und seiner Umgebung. Arch Oto Rhinol Laryngol Suppl I:53-62, 1989

30. Borei R, Passerini A: The megadolichobasilar anomaly. J Neurol Sci $1: 475-484,1964$

31. Mangham CA, Carberry JN, Brackman DE: Management of intratemporal vascular tumors. Laryngoscope 91:867-875, 1981

32. Curtin HD, Jensen JE, Barens L, May M: Ossifying hemangiomas of the temporal bone; evaluation with CT. Radiology 164:831835,1987

33. House WF: Surgical exposure of the internal auditory canal and its contents through the middle cranial fossa. Laryngoscope 71: 1363-1385, 1961

34. Rhoton AL: Microsurgery of the internal acoustic meatus. Surg Neurol 2:311-318, 1974

35. Samii M, Turel K, Penkert G: Management of seventh and eighth nerve involvement by cerebellopontine angle tumors. Clin Neurosurg 32:242-272, 1985 


\section{REVIEWER'S COMMENTS}

The authors have brought to our attention the relatively uncommon vascular tumors of the cerebellopontine angle that may mimic an acoustic neuroma. Surgeons approaching this area must be cognizant that these tumors exist and be ready to handle them when encountered. I, however, would take exception with the authors that the posterior fossa is the only way to approach these tumors. The second case had a long-standing, profound sensorineural hearing loss and would have done very well with a translabyrinthine excision. This approach provides far better access to the internal auditory canal contents and allows the facial nerve to be more easily identified and protected. It also gives adequate visualization of the cerebellopontine angle for control of any feeding vessels, particularly with the lack of any sizable tumor mass filling the space.

Herman Jenkins, M.D. 